\title{
POTENCIAL DO TURISMO DE BASE COMUNITÁRIA NA COMUNIDADE DA BARRA DO UNA, PERUÍBE/SP*
}

\author{
Mariana Clauzet ${ }^{1}$ \\ Alisson Peter Brito Dopona ${ }^{3}$ \\ Milena Ramires ${ }^{1}$ \\ Paula Chamy ${ }^{2}$
}

\section{RESUMO}

Em unidades de conservação de uso direto como as Reservas de Desenvolvimento Sustentável (RDS), as populações humanas podem desenvolver atividades econômicas de uso sustentável dos recursos naturais integrando conservação e modos de vida. O presente trabalho analisou o potencial do turismo de base comunitária da Reserva de Desenvolvimento Sustentável da Barra do Una (RDSBU), Peruíbe/ SP, área que integra o Mosaico de Unidades de Conservação Juréia-Itatins (MUCJI), baseando-se no conceito de sustentabilidade definido no Sistema Nacional de Unidades de Conservação (SNUC) e premissas do turismo de base comunitária. Foram realizadas 25 entrevistas com os moradores locais para obtenção de informações relacionadas às áreas naturais de potencial turístico existente na reserva, bem como as condições para o desenvolvimento do turismo de base comunitária. Os moradores entrevistados possuem idade média de 47 anos; $36 \%$ deles atuam na pesca artesanal e no comércio e $64 \%$ já realizam alguma atividade relacionada ao turismo. Foram indicados 07 pontos com potencial turístico na região: Praia da Deserta, Cachoeira do Paraíso, Praia do Caramborê, Rio Verde, Costão Rochoso, Rio Una e Cachoeira do Guilherme. Destes, dois dos pontos estão localizados na área da Estação Ecológica que por ser uma unidade de conservação restritiva não prevê atividade turística. O outro está inserido no Parque Estadual Itinguçu, onde o turismo já está sendo explorado. Os outros quatro pontos que pertencem legalmente à RDSBU foram caracterizados nesta pesquisa. Concluiu-se que a Vila Barra do Una tem potencial para desenvolvimento do turismo de base comunitária em pontos de praias, rios e cachoeiras, com natureza preservada e alta biodiversidade. Para desenvolvimento da atividade turística local, os dados demonstram que com melhorias em infraestrutura, uma alternativa para geração de emprego e renda voltada para a população local, é a organização do turismo de base comunitária no local.

Palavras Chave: Caiçaras; Reserva de Desenvolvimento Sustentável; Turismo de Base Comunitária

\section{ABSTRACT}

In conservation units of direct use as the Sustainable Development Reserves (RDS), human populations can use natural resources to develop economic activities for sustainable by

\footnotetext{
${ }^{1}$ Laboratório de Ecologia Humana, Programa de pós Graduação em sustentabilidade de ecossistemas costeiros e marinhos. Universidade Santa Cecília, Santos/SP. E-mail: mariana.clauzet@ gmail.com

2 Grupo de Pesquisa e Extensão em Conservação e Gestão de Recursos de Uso Comum (CGCommons/ NEPAM/UNICAMP), Rede Transformar. E-mail: paula.chamy@gmail.com

${ }^{3}$ Faculdade de Ciências Biológicas, Universidade Santa Cecília, Santos/SP. E-mail: alissonpeterbio@gmail.com

* Financiamento: PIBIC-UNISANTA.
} 
integrating conservation and livelihoods. This study analyzed the potential of communitybased tourism in a Sustainable Development Reserve of Barra do Una (RDSBU), Peruibe / $\mathrm{SP}$, an area that is part of the Protected Areas called "mosaic of Juréia-Itatins" (MUCJI), based on the concept of sustainability defined in the National Protected Areas System (SNUC) and assumptions of community-based tourism. 25 interviews were conducted with local residents to obtain information related to the natural potential tourism areas in the reserve as well as the conditions for the development of community-based tourism. Respondents residents have 47 years old in average; $36 \%$ of them work in artisanal fisheries and trade and $64 \%$ already do some tourism activity. They indicated 07 points with potential tourism in the region: the "Praia Deserta (Desert Beach), "Cachoeira do Paraiso" (Paradise Waterfall), "Praia do Camborê" (Caramborê Beach), "Rio Verde" (Green river), "Costão" (Rocky point), "Rio Una" (Una River) and "Cachoeira do Guilherme" (Guilherme's Waterfall). Of these, two of the points are located in the Ecological Station area that being a restrictive conservation unit does not provide tourism. The other is inserted into the Itinguçu State Park, where tourism is already being explored. The other four points in the legally RDSBU area were characterized in this study. It was concluded that the Barra do Una village has potential for development of community-based tourism in beaches, rivers and waterfalls points, with unspoiled nature and high biodiversity. For development of local tourism, the data show that with improvements in infrastructure, an alternative to generate employment and income aimed for the local population, is the organization of community-based tourism on site.

Keywords: Caiçaras; Reserve Sustainable Development; Community Based Tourism

\section{INTRODUÇÃO}

Nos últimos anos, a Vila Barra do Una, Peruíbe/SP, tem vivido a alteração constante da categorização ambiental da área onde se insere. Categorizada ora como Estação Ecológica, (ESEC), Unidade de Conservação (UC) de proteção integral, que não permite a exploração dos recursos, ora como Reserva de Desenvolvimento Sustentável (RDS), UC de uso direto. As ESEC's integram as UC's de Proteção Integral; são de domínio público e as áreas particulares precisam ser desapropriadas. Nesta categoria não é permitida nenhuma forma de uso dos recursos naturais da área preservada. Já as RDS's são categorias de UC's de uso sustentável, também são de domínio público, porém devem ter as áreas particulares desapropriadas somente quando necessário e permitem atividades locais de uso de recursos naturais para subsistência de populações humanas que podem viver dentro da área preservada. A alternância que se dá entre ESEC e RDS gera para os moradores uma situação de desconforto, uma vez que estas as duas categorias são totalmente distintas em relação às normas de uso dos recursos naturais locais.

Devido às características de uso do espaço das RDS's, as populações locais que nelas residem podem ser inseridas em programas de turismo de base comunitária nos quais elas apresentam seu patrimônio natural e cultural aos turistas. O turismo de base comunitária deve contribuir para uma melhor conservação e desenvolvimento, trazendo benefícios econômicos, sociais e culturais para todos os membros da comunidade (INSTITUTO ECOBRASIL, 2010).

Neste contexto, destaca-se que a realização de parcerias é condição essencial para o processo participativo. Diversos estudos mostram que os usuários de recursos naturais devem 
ser parte integrante dos processos de tomadas de decisão, pois, do contrário, as populações locais são submetidas a regras de uso impostas as quais não se identificam e podem estar equivocadas aos contextos locais (ADGER 2000; ARAÚJO E GELBECK, 2008; BEGOSSI, 2010).

A luta pela conservação na Barra do Una e seu entorno, teve seu ápice em 1986 com a criação da Estação Ecológica Juréia-Itatins (EEJI), período em que se discutia o Acordo Nuclear Brasil/Alemanha para instalação de usinas nucleares na região concomitantemente ao crescimento de movimentos ambientalistas nacionais e internacionais (NUNES, 2003).

Regulamentada pela Lei Estadual ${ }^{\circ} 5.649$ de 28 de abril de 1987, a EEJI não obedecia aos critérios exigidos de implementação em áreas de domínio público, ou desapropriadas para o mesmo fim, já que haviam populações ocupando a área há gerações. Com a criação da UC, iniciou-se uma série de conflitos entre moradores locais e o Estado (ROSA, 2007).

No Estado do Amazonas, em 1996, com uma situação conflituosa semelhante à EEJI, uma nova categoria de UC foi criada e implantada - a Reserva de Desenvolvimento Sustentável Mamirauá (RDSM), com o objetivo de manter a comunidade local nas terras que ocupam, permitindo a exploração dos recursos naturais de modo compatível com a conservação.

O Mosaico de Unidades de Conservação Juréia-Itatins foi criado e as ocupações foram regulamentadas, o que deu origem ao mosaico de UC's dada à conformação variada de áreas protegidas existentes. Em relação a Barra do Una, no ano de 2006 foi apresentado o projeto de Lei $\mathrm{n}^{\circ}$ 12.406, de 12 de Dezembro, que alterou a Lei $\mathrm{n}^{\mathbf{0}} 5.659$, modificando as áreas que formavam a ESEC. Porém, em 10 de junho de 2009 foi julgada uma Ação Direta de Inconstitucionalidade (ADIM), pois foi posta em "dúvida a eventual destruição do meio ambiente". Além disto, foi argumentado também que houve a "indispensabilidade do Estudo de Impacto Ambiental que afronta aos artigos 5, 24, 111, 144, 191 e 196, todos estes da Constituição Estadual". Com isso, a vila Barra do Una, voltou a fazer parte da ESEC, retirando direitos da comunidade de moradores locais à terra e às atividades econômicas relacionadas ao uso de recursos naturais (SÃO PAULO- DIÁRIO OFICIAL, 2010).

Novamente, em Abril de 2013, foi apresentado um novo projeto de lei, $\mathrm{n}^{\circ} 14.982$ para alterar o status da comunidade, mas foi julgado improcedente, pois: "não é possível a transformação de unidade de conservação de proteção integral, como é o caso da Estação Ecológica Juréia-Itatins, em nenhum tipo de unidade de conservação de uso sustentável" (SÃO PAULO-DIÁRIO OFICIAL, 2013).

Porém, finalmente, no dia 04 de junho de 2014, por votação unânime, a Barra do Una foi então reclassificada como RDS (SÃO PAULO-DIÁRIO OFICIAL, 2014). Além disso, tornou-se mais uma vez evidente a necessidade de incentivos para que todas as atividades desenvolvidas na área estivessem compatíveis com o interesse e tradições da população local em sintonia com o zoneamento e o Plano de Manejo da área (SNUC, 2006).

Conforme previsto no Sistema Nacional de Unidades de Conservação (SNUC), capítulo III, artigo 20: “As RDS's são áreas naturais que abrigam populações tradicionais, cuja existência baseia-se em sistemas sustentáveis de exploração de recursos naturais, 
desenvolvidos ao longo de gerações e adaptados às condições ecológicas locais e que desempenham um papel fundamental na proteção da natureza e na manutenção da diversidade biológica" (SNUC, 2006: 56).

Nesta categoria de UC podem ser desenvolvidas diversas atividades, como: pesquisa científica, educação ambiental, exploração dos recursos naturais, desde que com prévia autorização do órgão responsável pela unidade e em conformidade com o Plano de Manejo da área (SNUC, 2006).

Segundo o Ministério do Turismo, o turismo voltado para atrativos naturais e culturais, promove o bem-estar das populações envolvidas, utilizando de forma sustentável o patrimônio cultural e natural e incentivando a conservação e a consciência ambiental através da interpretação do ambiente (LINDBERG E HAWKINS 1995). Neste contexto, pode-se considerar as áreas das RDS's como locais propícios ao exercício do turismo de base comunitária.

Para Irving (2009) a participação da população local na elaboração do planejamento e implementação de projetos de turismo comunitário "representa um elemento essencial para a sustentabilidade das iniciativas e para garantia de conservação do patrimônio natural e cultural". A autora enfatiza que deve haver uma motivação por parte dos grupos sociais locais, para que possa atender às demandas de desenvolvimento local e contribuir para o protagonismo social, resultado do sentimento de pertencimento e do poder de influência sobre os processos de decisão.

Neste sentido, a Ecologia Humana e a Etnoecologia são linhas de pesquisa importantes, pois investigam as interações entre as populações humanas e o ambiente, com foco na expressão cultural de uma comunidade acerca de sua compreensão e interpretação sobre o mundo biológico (BOISCHIO, 1999; KIMMERER, 2002). O conhecimento de uma comunidade sobre a natureza, bem como o uso que fazem dos recursos naturais, pode ser transmitida de pessoa para pessoa e representa uma tradição intelectual entre gerações (HUNN, 1993). Segundo Marques (2001) a Etnoecologia é "o campo de pesquisa (científica) transdisciplinar que estuda os pensamentos (conhecimentos e crenças), sentimentos e comportamentos que intermediam as interações entre as populações humanas que os possuem e os demais elementos dos ecossistemas que as incluem, bem como os impactos ambientais dai decorrentes" (MARQUES, 2001:16).

$\mathrm{O}$ objetivo deste trabalho foi analisar as potencialidades da região para $\mathrm{o}$ desenvolvimento de atividades de turismo de base comunitária na Reserva de Desenvolvimento Sustentável da Barra do Una (RDSBU), associadas ao conhecimento ecológico local dos moradores.

\section{MATERIAIS E MÉTODOS}

Esta pesquisa foi desenvolvida na comunidade caiçara da Barra do Una na Reserva de Desenvolvimento Sustentável da Barra do Una - RDSBU, pertencente ao Mosaico de Unidades de Conservação Juréia-Itatins, situado no município de Peruíbe (SP) e que corresponde hoje a 1.487 hectares. Abrange áreas com necessidade de regulamentação 
fundiária, áreas de interesse turístico e áreas de enorme importância para a conservação da biodiversidade (Figura 1).

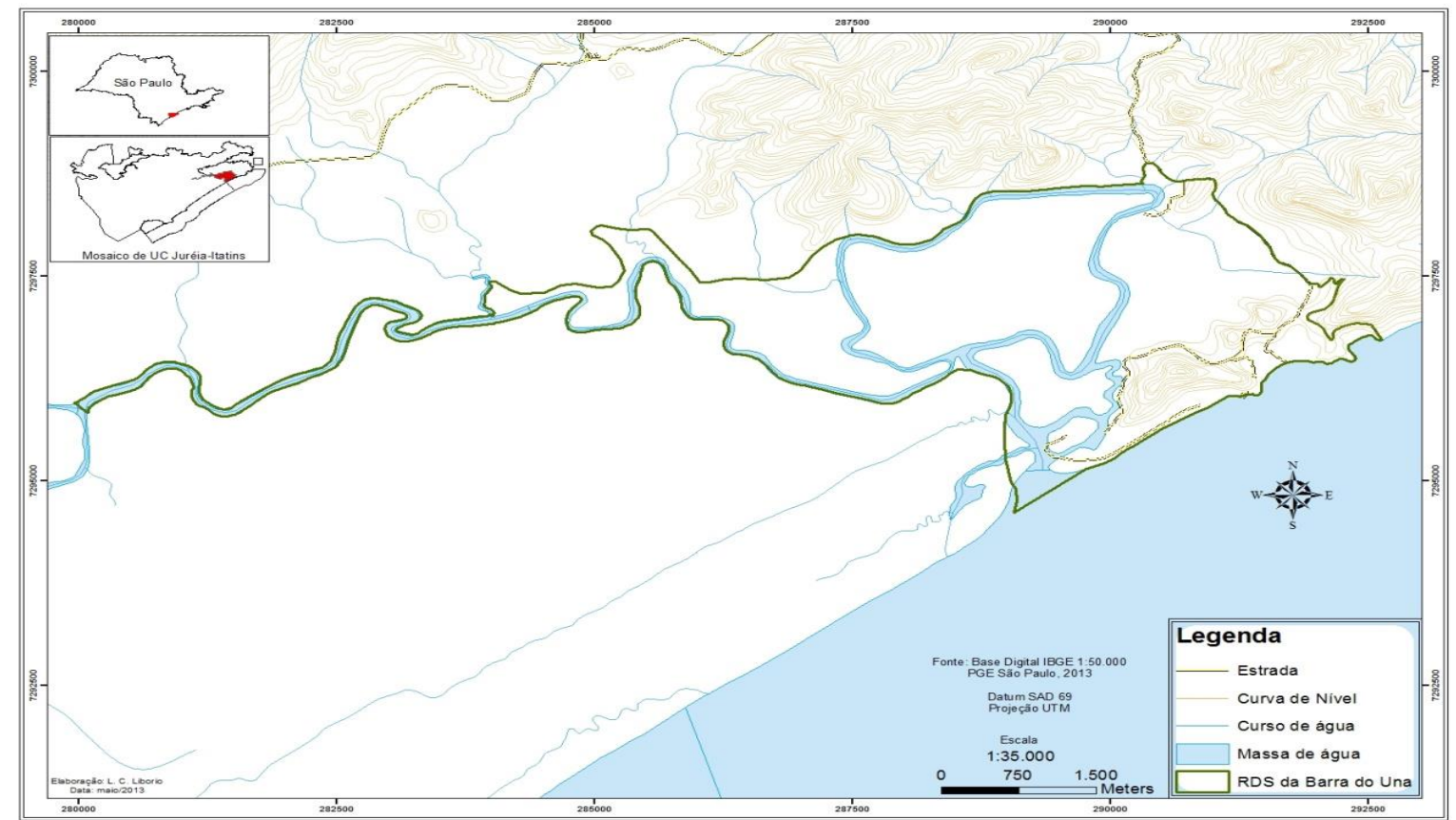

Figura 1: Localização da área de estudo, RDS Barra do Una, Peruíbe/SP (Fonte: Acervo Mosaico de Unidades de Conservação Jureia Itatins/ MUCJI).

Para a coleta de dados foram realizadas entrevistas com o auxílio de um formulário semi-estruturado, contendo questões abertas e fechadas sobre o turismo e a Reserva de Desenvolvimento Sustentável. Este método consiste na elaboração de perguntas que apresentam grande flexibilidade e permite aprofundar elementos que podem surgir durante a entrevista (ALBUQUERQUE, 2010).

Foram entrevistados apenas pessoas enquadradas nas categorias de: maiores de 18 anos e residência na região por mais de 10 anos. Desta forma, considera-se que os entrevistados têm conhecimento do seu ambiente e potencial para desenvolver práticas relacionadas ao turismo de base comunitária na RDS.

O trabalho de campo foi realizado entre os meses de Julho de 2013 e Janeiro de 2014, totalizando 25 entrevistas com moradores da RDS Barra do Una e 4 caracterizações de pontos de potencial turístico indicados pelos entrevistados. Os entrevistados responderam sobre quais os locais que podem ser explorados como roteiros turísticos na região e os mais citados foram caracterizados e descritos em relação ao acesso, distância da vila, paisagem, etc.

O esforço amostral foi definido com base no método "bola de neve" onde cada morador entrevistado, indicou outro morador ao final de sua entrevista e assim sucessivamente, até que se atingisse o maior número de moradores locais entrevistados.

\section{RESULTADOS}


Os 25 moradores entrevistados têm idade média de 47 anos, dos quais $36 \%$ atuam na atividade pesqueira artesanal e $20 \%$ no comércio. A maioria dos entrevistados (64\%) desenvolve alguma atividade relacionada ao turismo concomitante às suas atividades principais e $32 \%$ trabalham como guias, levando turistas de maneira informal aos locais de beleza natural da região.

Do total dos entrevistados, $36 \%$ não desenvolve nenhuma atividade relacionada com o turismo. Isto pode ter cunho na antiga categorização da vila da Barra do Una em ESEC, a qual não era permitido realizar este tipo de atividade. Atualmente sendo RDS, pode aumentar o número de moradores inseridos em atividades neste ramo.

Segundo $56 \%$ dos entrevistados, o principal benefício que o turismo pode trazer é o aumento da renda para as famílias, seguido de melhorias de infraestrutura (12\%), aumento de empregos $(12 \%)$ e para $8 \%$ dos entrevistados, a ampliação do conhecimento ambiental é uma questão importante, pois está associado a necessidade de capacitações para que os moradores atuem nas atividades de turismo (Figura 2).

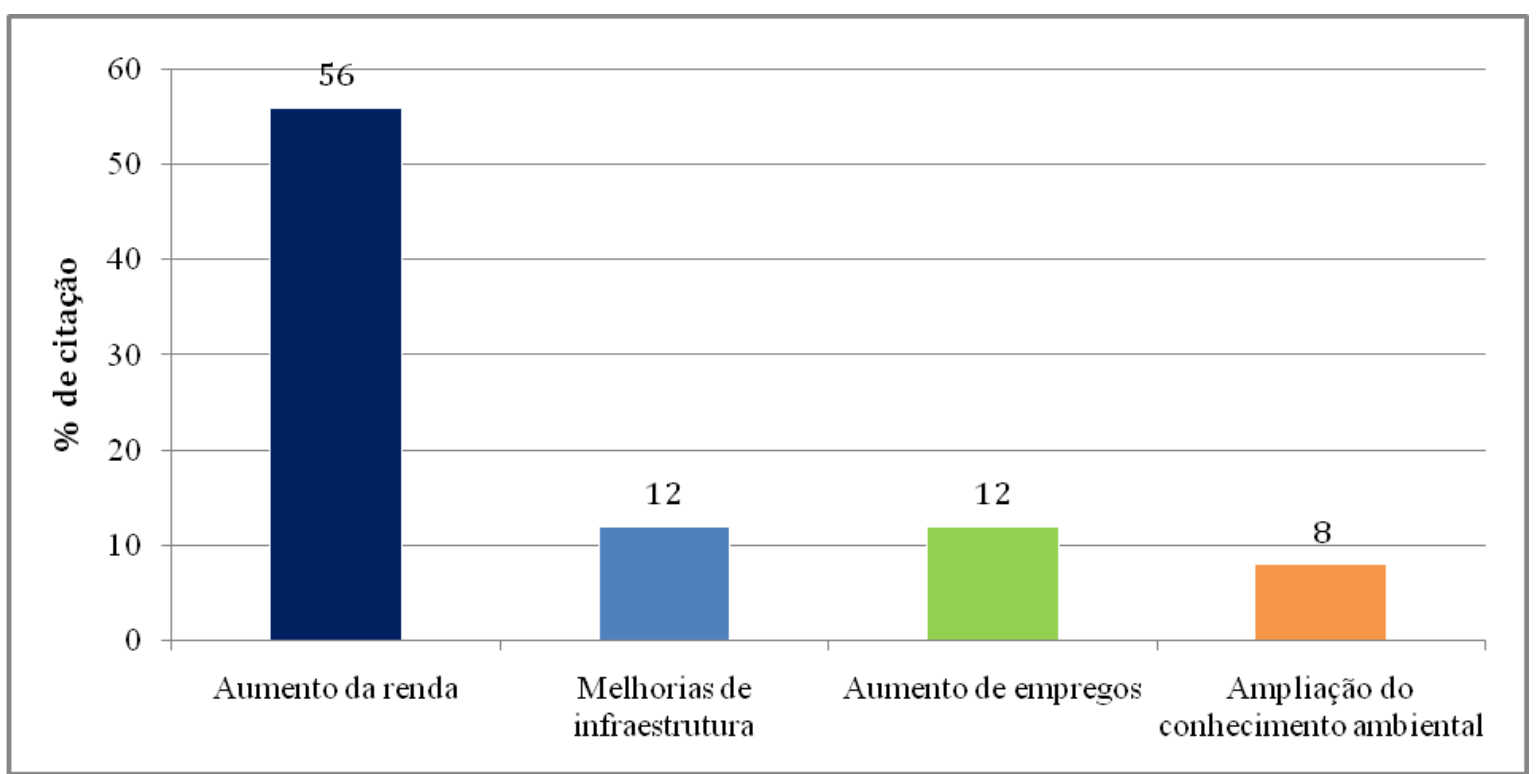

Figura 2: Potenciais benefícios que o turismo pode trazer a comunidade da Barra do Una, segundo os moradores locais.

Dos entrevistados, $52 \%$ gostariam de desenvolver apenas atividades relacionadas ao turismo ecológico como fonte de renda (e 36\% não), revelando o interesse pela atividade, principalmente, por acreditarem no potencial econômico vindo dela.

Neste contexto, destaca-se que $92 \%$ dos moradores entrevistados acreditam que a alteração do status de Unidade de Conservação de Estação Ecológica para Reserva de Desenvolvimento Sustentável pode trazer benefícios para a vila. Essa expectativa está relacionada diretamente com o fato da alteração de categoria permitir a permanência da comunidade e o uso tradicional dos recursos naturais (como a pesca) nas áreas protegidas.

Os entrevistados foram questionados sobre o que poderia ser melhorado na vila da Barra do Una, para que a recepção ao turista fosse bem realizada (Figura 3). 


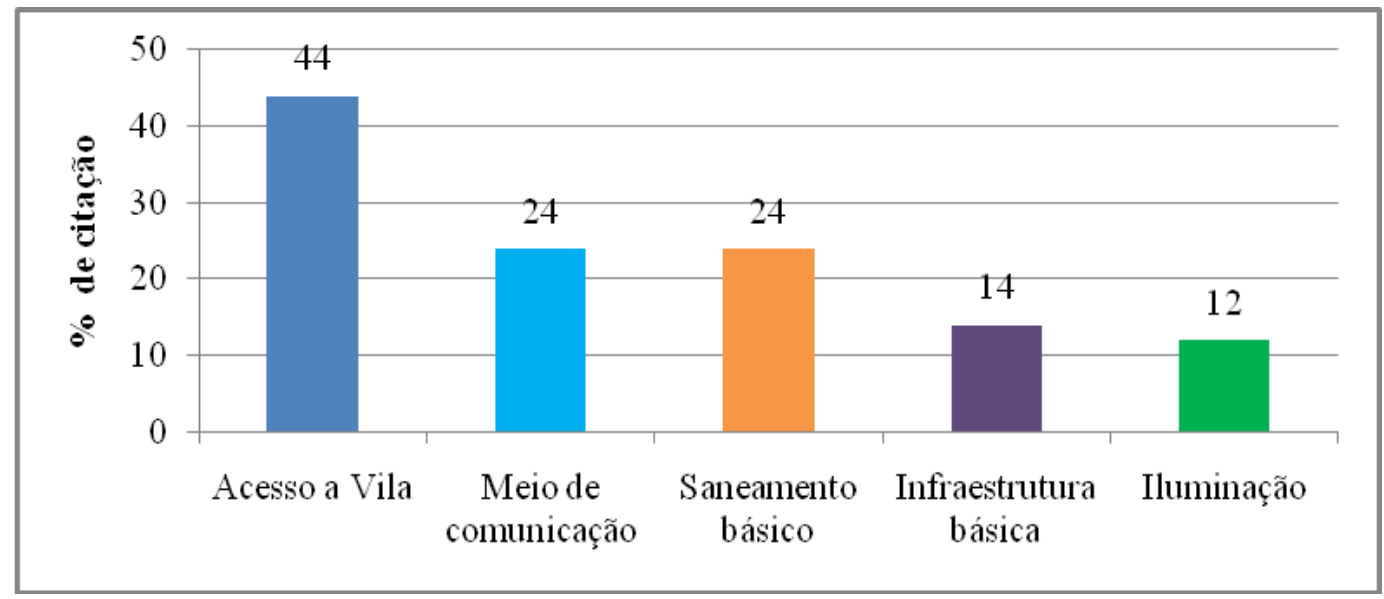

Figura 3: Melhorias de infraestrutura da Vila da Barra do Una necessárias para o receptivo turístico, segundo os moradores locais.

Os itens que foram mais citados, para serem melhorados na vila foram: o "Acesso à Vila" (44\%), que é muito precária, principalmente quando há chuva. Em seguida, a "Iluminação" e os "Meios de Comunicação" (24\%), pois na vila não há internet e sinal de celular. Para se comunicar, os moradores contam com dois telefones públicos, que muitas vezes não estão funcionando. Os resultados evidenciam que, na visão do morador local, para uma boa realização do turismo, é necessário também a colaboração das autoridades locais para dar suporte ao turista e à comunidade.

O turismo com a participação das comunidades e integrando diferentes esferas institucionais, não somente gera renda, mas também o desenvolvimento e a valorização social e cultural. Além disso, pode contribuir para reduzir a pressão sobre outros recursos naturais como, por exemplo, os pesqueiros, diminuindo a pressão de pesca (LOPES, 2011).

No total foram indicados 7 atrativos com potencial de exploração, incluindo praias, cachoeiras e rios. Dentre eles dois locais com grande porcentagem de citações (Cachoeira do Guilherme e Rio Verde), não foram caracterizados neste estudo por ocuparem a área da Estação Ecológica, onde não é permitida a exploração turística. E um terceiro local, a Cachoeira do Paraíso, está dentro dos limites do Parque Estadual Intiguçu, onde já ocorre a visitação guiada por monitores locais (Figura 4). 


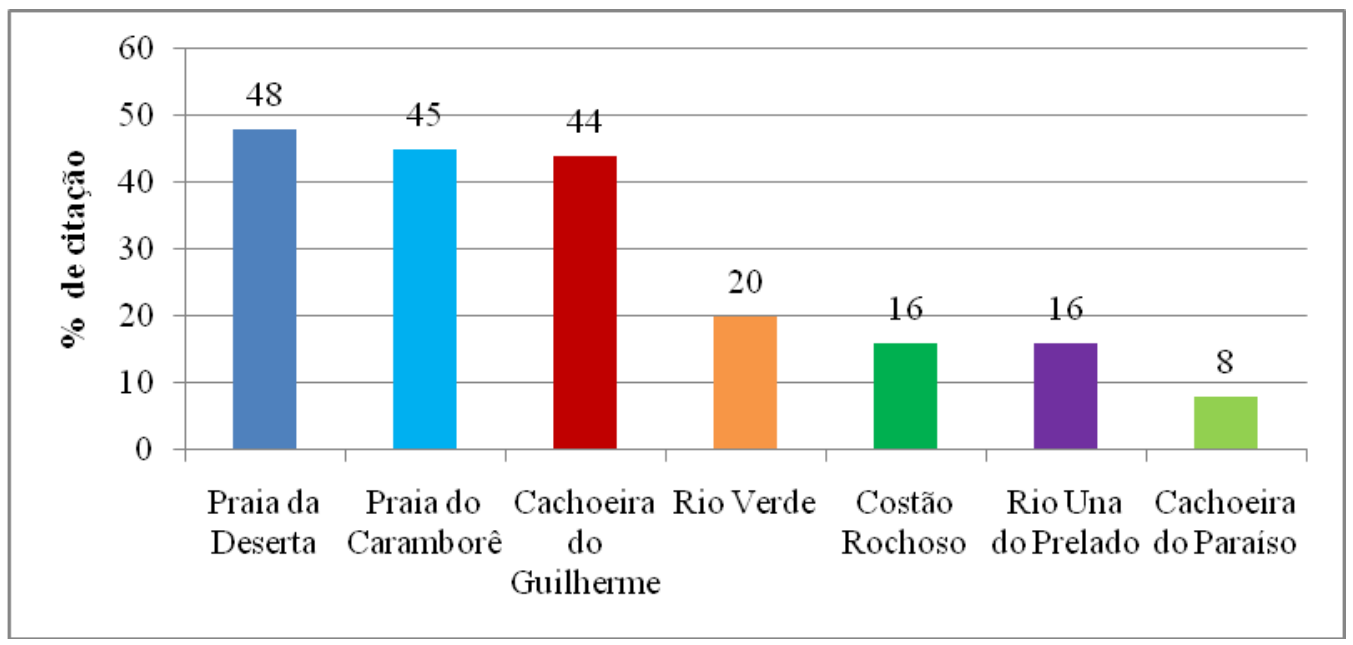

Figura 4: Pontos de potencial turístico, segundo moradores da Barra do Una.

Dos locais com potencial de exploração, os mais citados foram a Praia da Deserta (48\%), Praia do Caramborê (45\%), Costão Rochoso e Rio Una (16\%). Vale destacar o alto número de citações pelos entrevistados para os pontos da Cachoeira do Guilherme (44\%) e Rio Verde (20\%), especialmente pela sua beleza natural, e que estão inseridos na área da ESEC. A não permissão de visitação turística nestes pontos é considerada pela comunidade local um prejuízo ao desenvolvimento do turismo de base comunitária na vila Barra do Una.

Os pontos de potenciais turísticos de base comunitária mais citados pelos entrevistados foram caracterizados através da descrição do acesso a estes locais: distância estimada da vila do Una, tipo de vegetação encontrada, existência de rios próximos, presença de animais silvestres, se o local encontra-se dentro de alguma área de conservação, pontos positivos e negativos para o turismo, quem poderia participar de atividades naquele local, atividades que podem ser desenvolvidas, etc. Estas informações poderão ser úteis para os gestores do plano de manejo da RDSBU no caso de um futuro planejamento do turismo na região.

\section{Praia do Caramborê:}

Dentro da ESEC Juréia-Itatins, a aproximadamente 1,5 km da vila da Barra do Una, encontra-se a Praia do Caramborê (Figura5) (citada por $45 \%$ dos moradores) podendo ser alcançada por uma pequena trilha que rodeia o costão da praia da Vila, em um tempo médio de 30 minutos. A vegetação predominante na praia do Caramborê é de baixa estatura composta, principalmente, por arbustos de densidade variável, com árvores não muito altas, indicativo de vegetação de restinga, comum nas praias de Mata Atlântica.

Com apenas uma família vivendo no local, a praia possui grande beleza natural, tornando o lugar muito procurado por visitantes, tanto para fins de pesquisa como para lazer e prática de esportes, por exemplo: surf e canoagem. Porém, o acesso à praia requer um condicionamento físico razoável, o que restringe o acesso para turistas sedentários ou portadores de necessidades especiais. 


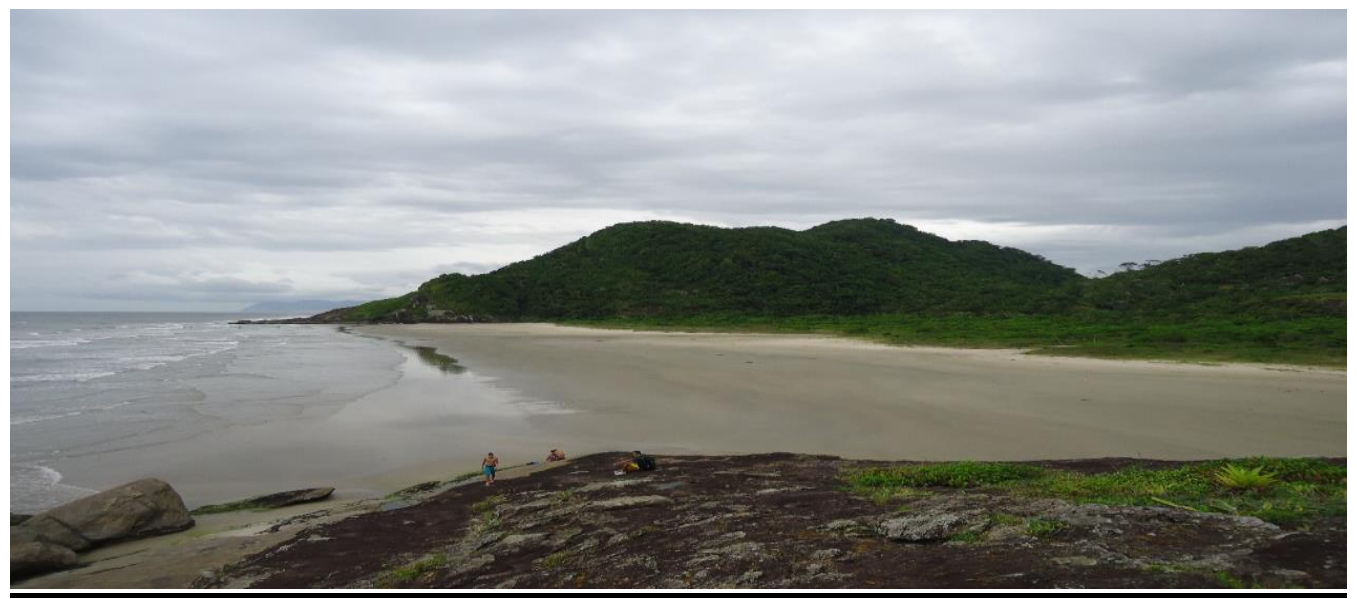

Figura 5: Foto ilustrativa da Praia do Caramborê, Barra do Una. (Arquivo pessoal de Janeiro de 2014).

\section{Praia da Deserta:}

A Praia da Deserta, citada por $48 \%$ dos entrevistados, se localiza a aproximadamente 2,4 $\mathrm{km}$ ao norte da praia da vila da Barra do Una, com acesso por trilha partindo da praia do Camborê, de dificuldade elevada. Em média com 10 minutos de caminhada em mata fechada, inclinada e alguns obstáculos que exigem cautela na realização da trilha. A praia é pequena com aproximadamente $300 \mathrm{~m}$, se limita entre dois costões e apresenta uma vegetação de restinga, de curta expansão até uma encosta com uma vegetação densa de floresta tropical que rodeia toda a praia. Possui natureza exuberante sendo que, segundo alguns moradores, é possível avistar algumas espécies de aves como a "Gralha Azul" (Possivelmente Cyanocorax caeruleus), Tiê-Sangue (que seria Ramphocelus bresilius) e o Caracará (Caracara plancus). Estas identificações foram feitas a partir dos nomes populares locais fornecidos e a comparação com a Lista de Aves do Brasil de 2009.

Não há presença de nenhum morador no local, mostrando ser um ótimo atrativo para turistas em busca lugares com elevado contato com a natureza e também para estudos de campo realizado por estudantes ou grupos de pesquisa (Figura 6).

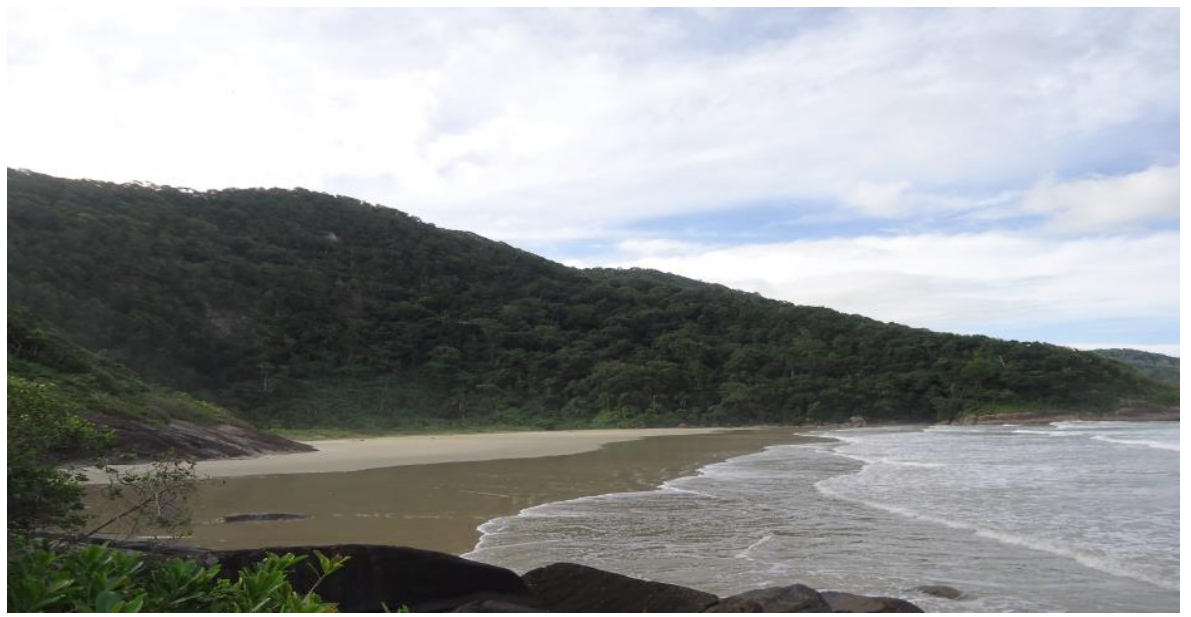

Figura 6: Foto ilustrativa da Praia da Deserta, Barra do Una. (Arquivo Pessoal de Janeiro de 2014) 


\section{Rio Una:}

O Rio Una, citado por $16 \%$ dos entrevistados, se localiza a aproximadamente $1,1 \mathrm{~km}$ da região central da vila. É caracterizado por uma vegetação de restinga e de manguezal, que o acompanha rio adentro. De fácil acesso, é possível chegar por barco, carro, ou por caminhada (dependendo das condições da maré). Sendo estuário, é grande a diversidade de animais que podem ser encontrados no local, uma vez que esse ecossistema serve de berçário para a vida marinha, além de ser fonte de alimentos para aves, mamíferos e répteis. O local é também propício para a prática da pesca esportiva e alguns turistas fazem uso de passeios de barco e jet ski.

Além do turismo, o ponto é um local de diversidade ecossistêmica (mangue, restinga e ambiente marinho) e um ambiente favorável para a pesquisa científica e prática de educação ambiental, para estudantes de universidades e escolas de ensino básico (Figura 7).

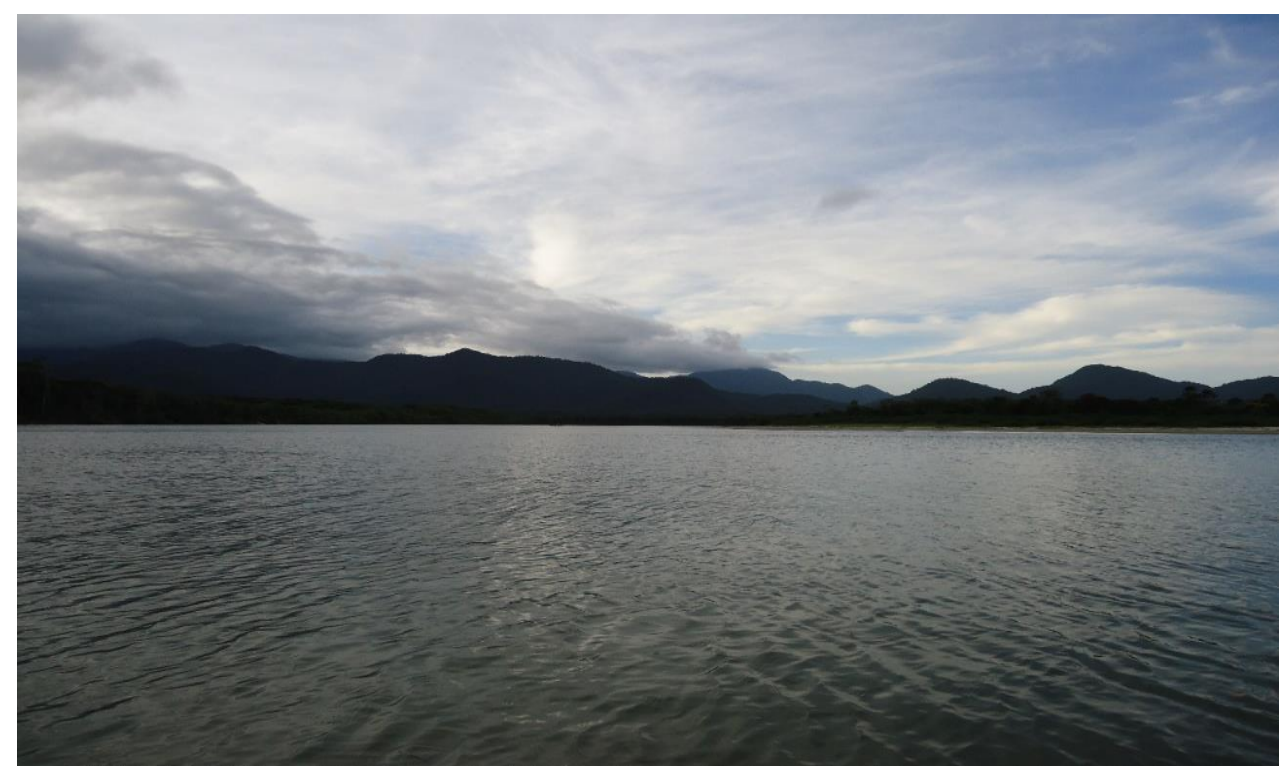

Figura 7: Foto ilustrativa do Rio Uma (Arquivo pessoal de Janeiro de 2014).

\section{CONCLUSÕES}

A Barra do Una mostrou ter um grande potencial para as atividades do turismo de base comunitária, com muitas praias, cachoeiras, rodeadas por uma natureza de alta biodiversidade. Porém, a comunidade da vila da Barra do Una carece de melhorias para que o turismo se torne uma atividade organizada e eficiente na geração de renda e benefícios locais. Melhorias que se iniciem por atender às necessidades de acesso, saneamento básico, infraestrutura e investimento na formação de moradores para a demanda turística e devem ser supridas por parte dos órgãos gestores. Neste contexto, o turismo de base comunitária poderia desencadear a justa distribuição de benefícios para a comunidade e o desenvolvimento local. 


\section{BIBLIOGRAFIA}

ADGER, W. N. Social and ecological resilience: are they related? Progress in human geography, 24 (3), 347-364. 2000

ALBUQUERQUE, U. P. L; CUNHA, R. F. P; CRUZ, L. V. F. Métodos e técnicas na pesquisa etnobiológica e etnoecológica. Recife - PE: NUPEEA, Volume 1. 2010

ARAUJO, G. P; GELBECKE, D. L. Turismo Comunitário: uma perspectiva ética e educativa de desenvolvimento. Revista Turismo Visão e Ação. 2008

BEGOSSI, A. Small-Scale Fisheries in Latin America: Management Models and Challenges. MAST, v. 9 (2), p.7-31. 2010

BOISCHIO, A. A. P. Poluição de ecossistemas aquáticos e consumo das cadeias alimentares em comunidades de pesca e mariscagem: como a ecologia humana pode ser combinada com a etnoecologia. In: Anais I Encontro Baiano de Etnobiologia e Etnoecologia.1999.

HUN, E. What is traditional ecological knowledge? In: Willians, N.M. e Baines, G. (Ed.) Tradicional Ecological Knowledge: Wisdom for sustainable development. Centre for Resource and Studies. Australia National University. p. 13 - 15. 1993.

INSTITUTO ECO-BRASIL. Jul. 2014. Disponível

em:<http://www.ecobrasil.org.br/publique/cgi/cgilua.exe/sys/start.htm?infoid=352\&sid=64>

Acesso: 01/07/2014.

IRVING, M. Reinventando a reflexão sobre turismo de base comunitária. In: Bartholo, A. R; Sansolo, D. G; Bursztyz, I. (Org.). Turismo de Base Comunitária: diversidade de olhares e experiências brasileiras. Rio de Janeiro: Ed. Letra e Imagem, 2009.

KIMMERER, R. W. Weaving tradicional ecological knowledge into biological education: a call to action. Bioscience 52 (5): 432-438. 2002

LINDBERG, K.; HAWKINS, D. E. Ecoturismo um guia para planejamento e gestão. 3 ed. São Paulo: Senac,. 290 p. 1995

LOPES, P. F. M; SILVANO, R. A. M.; BEGOSSI, A. Extractive and Sustainable Development Reserves in Brazil: resilient alternatives to fisheries? Journal of Environmental Planning and Management. 54 (4): 421-443. 2011

MARQUES, J. G. Pescando pescadores: ciência e etnociência em uma perspectiva ecológica. NUPAUB, USP, São Paulo. 2258 p. 2001

NUNES, M. Do passado ao futuro dos moradores tradicionais da EEJI.(2003). Dissertação de Mestrado. Departamento de Geografia, FFLCH/USP.

ROSA, F. P. Nativo Mudo e o contraponto da gestão participativa e do turismo de base comunitária na reserva de desenvolvimento sustentável barra do una - Mosaico da Juréia - Itatins. Trabalho de Conclusão de Curso (Graduação) - UNESP, SP. p. 67. 2007

SÃO PAUlO. Diário Oficial Estado de São Paulo. Diário de Justiça Eletrônico Caderno Judicial - $\mathbf{1}^{\mathbf{0}}$ Instância - Interior - Parte II. São Paulo, Ano IV - Edição 845. p 1732. Dezembro, 2010.

SÃO PAUlO. Diário Oficial Estado de São Paulo. Diário de Justiça Eletrônico Caderno Judicial - 2º Instância. São Paulo, Ano VII - Edição 1557. p 609, 610. Dezembro 2013. 
SÃO PAUlO. Diário Oficial Estado de São Paulo. Diário da Justiça Eletrônico Caderno Judicial - $1^{\circ}$ Instância - Interior - Parte II. São Paulo, Ano VII - Edição 1684. p 2196. Julho 2014.

SISTEMA NACIONAL DE UNIDADES DE CONSERVAÇÃO - SNUC. Relatório de Unidades de Conservação. 56 p. 2006 